\title{
Characteristics of diverted solid waste in Kumasi: A Ghanaian City
}

\author{
Adam Wahabu ${ }^{1}$, Sampson Oduro-Kwarteng ${ }^{2}$, Isaac Monney ${ }^{3,}$,, Prosper Kotoka ${ }^{4}$ \\ ${ }^{1}$ Waste Management Department, Tamale Metropolitan Assembly, Tamale, Ghana \\ ${ }^{2}$ Department of Civil Engineering, Kwame Nkrumah University of Science and Technology, Kumasi, Ghana \\ ${ }^{3}$ Department of Environmental Health and Sanitation Education, University of Education Winneba, Mampong-Ashanti, Ghana \\ ${ }^{4}$ Waste Management Department, Kumasi Metropolitan Assembly, Kumasi, Ghana
}

\section{Email address:}

monney.isaac@gmail.com (I. Monney)

\section{To cite this article:}

Adam Wahab, Sampson Oduro-Kwarteng, Isaac Monney, Prosper Kotoka. Characteristics of Diverted Solid Waste in Kumasi: A Ghanaian City. American Journal of Environmental Protection. Vol. 3, No. 5, 2014, pp. 225-231. doi: 10.11648/j.ajep.20140305.13

\begin{abstract}
Waste diversion from landfills has generally been neglected in the developing world despite its potential to prolong the lifespan of landfills and generate revenues. This study aims at characterizing diverted solid waste fractions at communal collection points in seven communities and determining the trends in landfilled solid waste due to the Pay-As-You-Throw (PAYT) mechanism. It is based on quantitative measurements of diverted waste by informal waste pickers at communal collection points in seven communities in the Kumasi metropolis and analysis of landfilled waste records prior to and after the introduction of the PAYT mechanism. The study shows a daily diversion rate of $19.4 \pm 9.2 \mathrm{~kg}$ per informal waste picker per day with no statistically significant difference $(\mathrm{p}=0.29)$. This constitutes just $0.5 \mathrm{w} / \mathrm{w} \%$ of the total waste stream at communal collection points. The diverted waste is dominated by plastics (50\%) and metals (29\%). Generally, the diverted waste quantities are hugely dependent on the storage capacities of the informal waste pickers while the types of recovered items depend on readily available market. The introduction of the PAYT system, as observed from the study, immediately caused a decline (28\%) in waste disposed of at communal collection points but steadily appreciated with time (26\% and $13 \%$ consecutive reductions in subsequent years). The study recommends support for the informal sector, Public-Private Partnerships for waste recycling and intensive public education on PAYT mechanism prior to and after its introduction.
\end{abstract}

Keywords: Diverted Solid Waste, Wastepicking, Landfill, Pay-As-You-Throw, Kumasi

\section{Introduction}

Rapid urbanisation rates coupled with rising living standards, particularly across the developing world, have left city authorities with the grueling task of having to collect and safely dispose of huge quantities of solid waste on daily basis [1]. Even with more than half of their annual budget expended on this all-important service and the involvement of private contractors, certain fractions of municipal solid waste remain uncollected [2-4]. The situation is not different from Ghana's second largest city, Kumasi, where approximately 1,500 metric tonnes of solid waste is generated each day [5]. Despite having an engineered landfill site for waste disposal, financial and technical constraints, have rendered absolute collection and disposal of this enormous quantity of waste unattainable and about a third of the municipal solid waste remains uncollected daily [6].
Consequently, repulsive sights of malodorous and pest-infested heaps of solid waste are still present in some parts of the city similar to that reported in other cities in the country and other neighbouring countries [2,7]. Meanwhile, recent studies [8-11] have shown that solid waste management has evolved from the conventional practice of collection and disposal of waste and now incorporates series of cost-saving and natural resource-conserving options such as source reduction, reuse, recycling and waste-to-energy which generally divert waste from landfill sites. Particularly, composting of organic solid waste, which makes up a significant proportion of waste in the developing world has the potential to reduce emissions of toxic gases generated at landfill sites [12]. This, and other options, as Poulsen [13] argues, are gradually making landfills in developed countries redundant and would in the future render them transitory storage sites for specific waste materials pending recycling. 
The situation is different in the developing countries where waste is collected with minimal or without diversion from landfills for recycling. Hence, the debate on ensuring drastic reduction in landfilled waste in the developing world is very crucial.

Generally, diversion of waste from landfills remains a hugely neglected issue in Ghana even though it has the potential to reduce landfilled waste and reduce the current costs associated with solid waste management services [14-16]. Findings from a recent study in Kumasi, Ghana, point out that, retrieval of only plastics from the solid waste stream for reuse and recycling purposes is solely carried out by the informal sector without any support from the government despite having a huge potential to generate revenue and create employment [17]. In addition, results of composition analysis on solid waste generated in Kumasi and other urban centres across the country indicate that other components could be diverted from landfills for use. Although waste diversion evidently has the potential to reduce the proportion of waste eventually landfilled and hence prolong the lifespan of landfills [18], its actual contribution to waste reduction and its composition in Ghana remains relatively unexplored. It therefore becomes paramount that this knowledge gap is filled to provide city authorities a persuasive evidence to shift their focus to this strategy.

It is noteworthy however that, waste reduction techniques have not been utterly neglected by authorities in the Kumasi Metropolis in their efforts to effectively manage solid waste in the city. In 2008, in an attempt to recover some of the funds injected into collection of solid waste and possibly compel residents to reduce the quantity of waste disposed of, the Kumasi Metropolitan Assembly (KMA) introduced a unit pricing system, commonly practiced in Europe and America, where residents are charged a fee for waste collection based on the quantity of waste intended for disposal generically referred to as Pay-As-You-Throw (PAYT)[19]. This approach, in its initial implementation stage, was met with opposition from the general public resulting in indiscriminate disposal of waste at unapproved sites. Though it has been touted generally as a commendable approach to generate revenue from waste collection, the actual effects of this technique on reducing landfilled waste quantities have not been investigated for informed decision making, possible improvement and replication in other areas.

Against this background, this study is based on two key objectives: to characterize diverted solid waste fractions and to determine the trend and possible reduction in landfilled solid waste due to PAYT.

\section{Description of the Study Area}

Kumasi is Ghana's second largest city after the national capital, Accra (Figure 1). It is the capital of the Ashanti region and has an estimated population of more than 2 million people - almost twice the estimated population in $2000[5,20]$. The city spans a total area of approximately 254square kilometers and is noted in the West African sub-region for its blossoming commercial activities. It has a climate of the sub-equatorial type having double maxima rainfall regime of about $214.3 \mathrm{~mm}$ in June and $165.2 \mathrm{~mm}$ in September. Averagely the temperature ranges between 21.5 to $30.7^{\circ} \mathrm{C}$ and humidity averages $84.16 \%$ at 09:00 GMT and $60 \%$ at 15:00GMT.

Being a metropolitan area, it has ten administrative sub-metros viz. Asokwa, Manhyia, Bantama, Nhyiaeso, Oforikrom, Subin, Kwadaso, Suame, Asawase and Tafo representing districts. Out of these, the first six are vibrant while the remaining four are relatively dormant owing to lack of resources. The metropolis has an engineered landfill site, though it operates under suboptimal conditions, which began operations in 2004. The site is a 100-acre piece of land and receives solid waste as well as special waste from the metropolis. Solid waste ending up at the site emanates from communal containers placed at vantage points in various communities in addition to that collected from door-to-door services, commercial centres and institutions within the metropolis.

\section{Methodology}

For the purpose of this study, seven communities located in two out of the six vibrant sub-metros were selected. Five communities, namely, Ayigya, Ayigya-zongo, Gyenyase, Kentinkrono, and Bomso were sampled from the Oforikron sub-metro and two from Asokwa sub-metro namely Kotei and Atonsu. Quantitative field measurements of diverted solid waste by seven informal waste pickers at communal container sites were carried out in November and December, 2011, at stipulated periods to determine its quantity and composition. The diverted solid wastes were deliberately allowed to accumulate over specific periods of time to obtain an appreciable quantity for the quantitative analyses. Altogether, diverted solid waste at each of the seven communal waste collection points were analysed on three different occasions throughout the study period. With a known accumulation period, the quantities of waste at the end of this period were converted into average daily diverted solid waste ( $\mathrm{Dw}$ ) by dividing the total waste accumulated at the end of the accumulation period by the number of days within that period. This is shown in Equation 1 below:

$$
D_{w}=\frac{Q_{p}}{d}
$$

Where Dw = Daily diverted solid waste by an informal waste picker

Qp = Quantity of waste accumulated within a period of time

$\mathrm{d}=$ number of days within the accumulation period

The composition of diverted solid waste was categorised into nine major components, namely, plastics, metals, glass/bottles, wood, foam, leather, ceramics, rubber and fibres.

The proportions of each component (Pi), expressed as a percentage of the total weight of diverted solid waste for a 
particular accumulation period was computed from Equation 2:

$$
P_{i}=\frac{W_{i, p}}{Q_{p}} \times 100 \%
$$

Where $\mathrm{Pi}=$ Proportion of the ith component of the diverted solid waste

Wi,p = Weight of the ith component within the accumulation period, $\mathrm{p}$

$\mathrm{Qp}=$ Quantity of waste accumulated within the period, $\mathrm{p}$

Total amount of waste generated was computed from the sum of diverted solid waste quantity from communal containers and landfilled waste from communal containers emanating from the study communities during the study period. Diverted solid waste in this study therefore refers to the waste separated from the solid waste stream at the communal collection points. The proportion of diverted solid waste was therefore computed as the ratio of diverted solid waste quantity to the total solid waste generated expressed as a percentage. Although, there could be waste picking at the landfill site and probably from commercial centers and door-to-door collection of waste, this study only considers diverted solid waste from the communal collection points.

Further, secondary data from landfill records at the Dompoase landfill site was obtained for five out of the seven study communities, namely, Kotei, Ayigya, Kentinkrono, Gyenyase and Atonsu which had monthly waste disposal data from 2007 to 2010 .

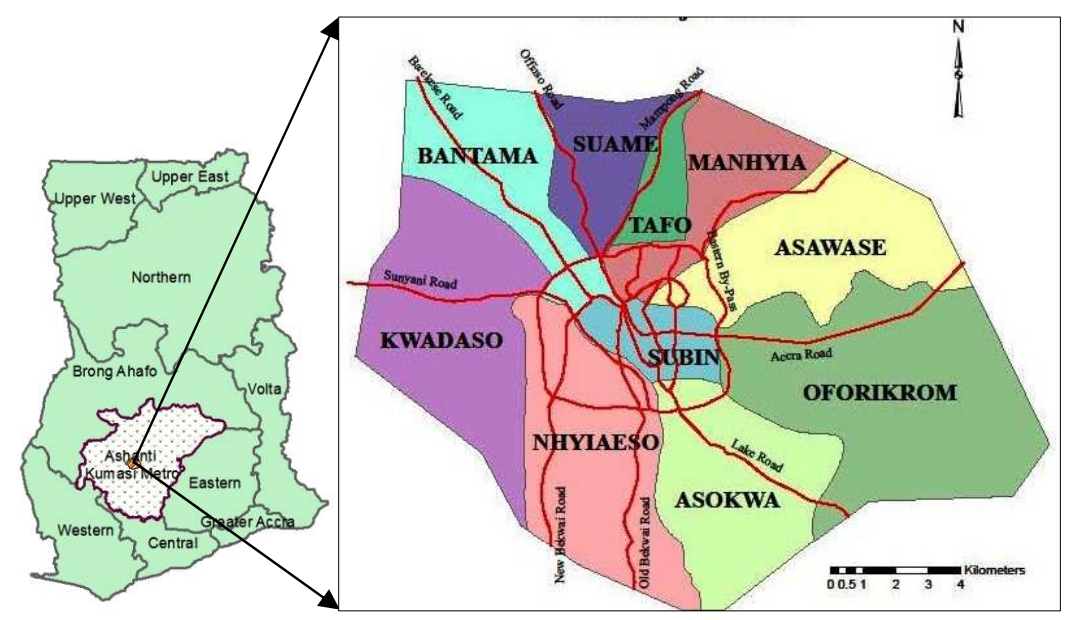

Figure 1. Map of Ghana showing the Kumasi Metropolitan Assembly (Adapted from http://mci.ei.columbia.edu/)

\subsection{Statistical Analyses}

Descriptive statistics, namely, mean, median, lower quartile, upper quartile, standard deviations were computed and plotted for the daily diverted solid waste from the study communities using Microsft Office Excel 2010. Single factor Analysis of Variance (ANOVA) was used to determine the statistical significance of the variation in daily diverted solid wastes among the study communities at 5\% significance level. This was also used to test the statistical significance of the variation between waste disposal quantities prior to and after the introduction of PAYT mechanism.

\section{Results and Discussion}

\subsection{Quantity and Composition of Daily Diverted Solid Waste from Study Communities}

The results of the study, as shown in Figures 2 and 3, indicate that on the average, $19.4 \pm 9.2 \mathrm{~kg}$ of solid waste is diverted daily by an informal waste picker from each communal collection point in the seven study communities, with a range of $5.9-42.8 \mathrm{~kg} /$ day. Averagely, maximum daily diverted solid waste was recorded at Ayigya Zongo $(23.5 \pm 14.6 \mathrm{~kg} /$ day $)$ and Atonsu $(23.5 \pm 12.5 \mathrm{~kg} /$ day $)$ while the minimum was recorded at Gyenyase $(9.7 \pm 5.0 \mathrm{~kg} /$ day $)$.

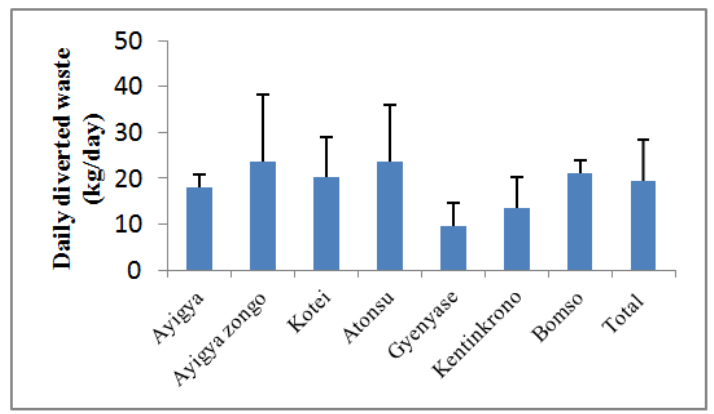

Figure 2. Average daily diverted solid waste by informal waste pickers in study community

This suggests that an average of approximately 6 tons of solid waste is diverted annually at each of the communal collection points in the study communities, based on six days per week collection of diverted solid waste. Each informal waste picker makes an average income of about 120 Ghana Cedis (US\$40) a month for their livelihood from these diverted materials. By inference, this could result in the diversion of about 300tons of solid waste per year from the landfill site, assuming that the practice is replicated in say, 
100 communal waste collection points in Kumasi. This translates into a cost savings of about $\mathrm{GH} \phi 18,000$ ( $\approx$ US $\$ 5,300$ ) to the City Authority (KMA) based on a unit collection and disposal cost of GHф30 ( $\approx$ US\$9) per ton of waste. However, larger quantities of solid waste can be potentially diverted if there is a readily available market for all types of plastics, metals and other materials and the practice is carried out in various homes, at commercial centers and in various institutions. Some of the plastics were not diverted due to contamination with other waste and unavailable market for them.

As Figure 3 depicts, the daily diverted solid waste quantities in Ayigya Zongo showed the highest variation from the mean $(23.5 \pm 14.6 \mathrm{~kg} / \mathrm{day})$ in contrast to Bomso which had the minimum deviation from the mean $(21.2 \pm 2.8 \mathrm{~kg} /$ day $)$. This indicates consistency in the quantities of diverted solid waste in Bomso compared to Ayigya Zongo although the former had a relatively higher mean value than the latter. In general, the study found no statistical significance $(p=0.29)$ in the variation of daily diverted solid waste among all the study communities. This could be attributed to the fact that all the study areas are predominantly within the low income bracket and therefore have similar waste characteristics.

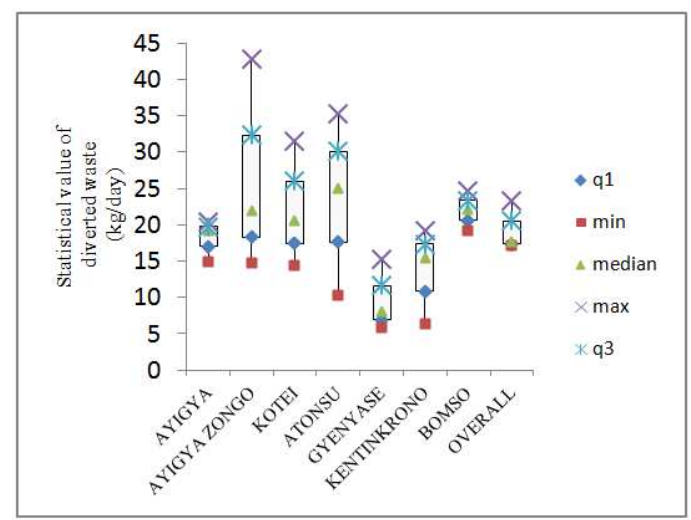

Figure 3. Distribution of daily diverted solid waste by informal waste pickers in study communities

Table 1. Diverted solid waste fractions in study communities

\begin{tabular}{|c|c|c|c|c|}
\hline Community & $\begin{array}{c}\text { Waste disposed } \\
(\mathrm{kg} / \mathrm{day})\end{array}$ & $\begin{array}{c}\text { Diverted solid waste by an } \\
\text { informal waste picker (kg/day) }\end{array}$ & Total Waste generated (kg/day) & Diverted fraction (w/w\%) \\
\hline Ayigya \& Ayigya Zongo & 2024.8 & 22.3 & 2047.1 & 1.09 \\
\hline Bomso & 2729.3 & 21.2 & 2750.5 & 0.77 \\
\hline Kotei & 1974.3 & 20.2 & 1994.5 & 1.01 \\
\hline Gyenyase & 5120.0 & 9.7 & 5129.7 & 0.19 \\
\hline Kentinkrono & 1693.9 & 13.6 & 1707.6 & 0.80 \\
\hline Atonsu & 7672.9 & 23.5 & 7696.4 & 0.31 \\
\hline
\end{tabular}

The estimate of diverted solid waste quantities as a fraction of the total waste collected at the communal collection points in the study communities shows that daily diverted solid waste fractions range between $0.2 \mathrm{w} / \mathrm{w} \%$ and $1.1 \mathrm{w} / \mathrm{w} \%$ with an overall average of $0.5 \mathrm{w} / \mathrm{w} \%$ (Table 1 ). This constitutes an insignificant proportion of the average total waste stream in the study communities of 3.6tons. It is also lower than those reported in China (17-38\%), UK (26\%), France $(24 \%)$ and Spain (10\%), Mexico (10\%), India (15\%) and Pakistan (27\%) [18, 21-22]. The diversion rates from this study is predictably lower than those reported in the literature above since it considers diverted solid waste from only communal points. Further, as gathered from the interactions with the informal waste pickers and field observations, the low diversion rates is attributable to lack of sufficient and secured storage space for recovered items at the communal collection points which, in some cases, results in theft of recovered items. None of the communal collection points was fenced and passers-by could easily get access to the recovered items. Consequently, the waste pickers are compelled to recover only a small proportion of items that they can securely store for resale. It could be perceived, without a stretch of imagination that, though the informal waste pickers have the potential to contribute largely to reducing landfilled waste, they are constrained by lack of resources to effectively carry out their activities and are also not given the needed support by city authorities. These, in addition to a host of other factors, hamper the efforts of informal waste pickers to divert significant quantities of waste from landfills.

Diverted solid waste from the study communities were generally dominated by two key components, viz. plastics (50\%) and metals (29\%), together making up almost $80 \%$ of the total diverted solid waste stream. Meanwhile, available studies [6, 23] have shown that, more than half $(55-61 \%)$ of the solid waste stream in Kumasi is organic in nature while plastics $(7-10 \%)$ and metals $(2-3 \%)$ constitute insignificant proportions. It is therefore evident from this study that, much attention is rather focused on diverting items that constitute minor fractions in the total waste stream most probably due to the market availability for such items. In order to achieve far greater reduction in the landfilled waste, there is the need to focus attention on diverting organic materials that constitute a greater part of the waste stream through the establishment of composting plants through Public-Private Partnerships to create the requisite market.

Ayigya recorded the highest proportion of plastics in the diverted solid waste while Kotei recorded the highest proportion metals in diverted solid waste. The variation of daily quantities of diverted plastics $(\mathrm{p}=0.25)$ and diverted metals $(p=0.78)$ within the study communities showed no statistical significance, implying similar average quantities in diverted waste in the study communities. 


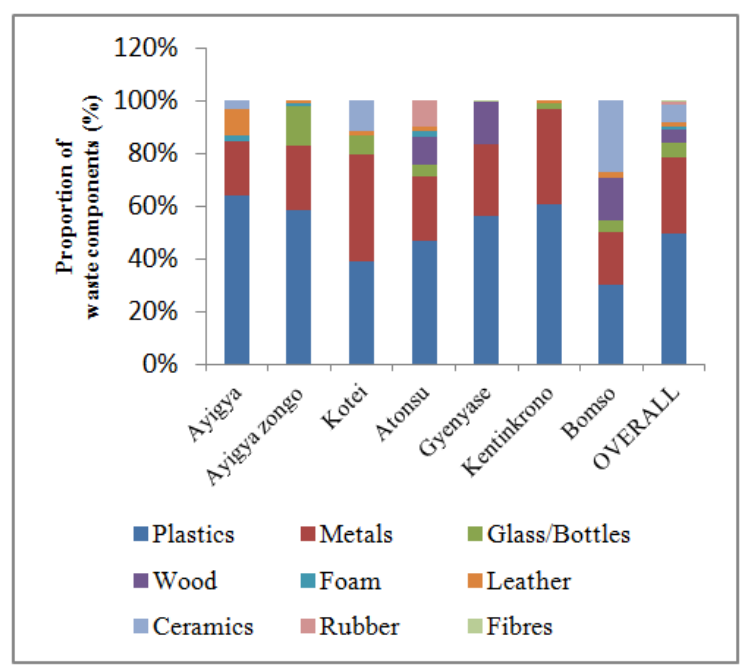

Figure 4. Composition of diverted solid waste at collection points

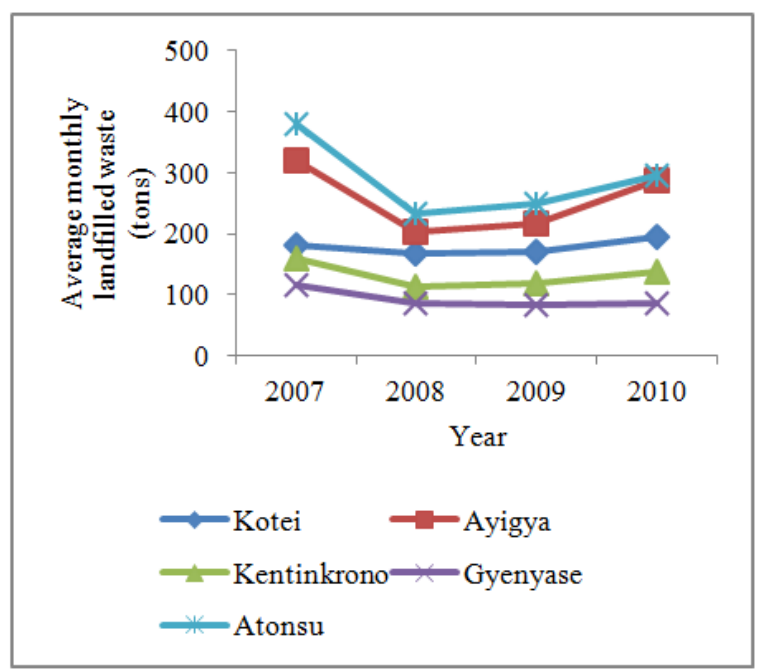

Figure 5. Trends in average monthly landfilled waste in five study communities

(Landfilled waste for Ayigya comprises of both Ayigya and Ayigya Zongo)

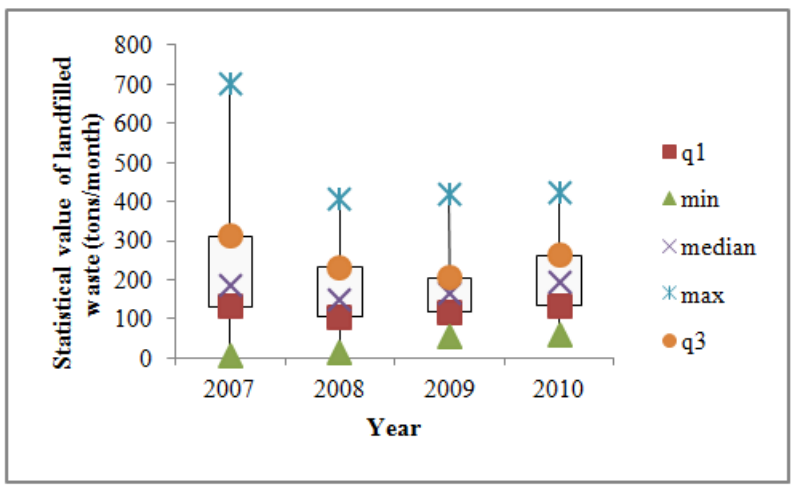

Figure 6. Overall year-on-year analysis of monthly landfilled waste

The pattern of average monthly landfilled waste, as shown in Figures 4 and 5, generally indicates a reduction of landfilled waste from the communities just after introduction of the PAYT mechanism (in 2008). Conversely, it increased marginally in the subsequent years (2009 and 2010) but had generally not yet attained the initial quantities of landfilled waste in 2007 except in Kotei (Figure 4). For Kotei, the increase in 2010 could be due to the fact that many residents have come to accept the PAYT system, and therefore throw most of their waste into the communal containers.

Monthly landfilled waste from the study communities shows lower and more consistent values between 2008 and 2010 as compared to the wide variation in 2007. Considering that, diverted solid waste from the communal disposal points constitute an insignificant proportion $(0.5 \%)$ of the total generated waste stream, it becomes evidently clear that the introduction of the PAYT method has influenced waste disposal patterns at communal disposal points. Conceivably, the reduction in the landfilled waste between 2007 and 2008 is due to residents' resistance to the PAYT system. More so, there could be the possibility that residents have actually reduced the amount of waste intended for disposal or resorted to open dumping of waste into drains and open spaces due to the levies collected at the communal disposal sites.

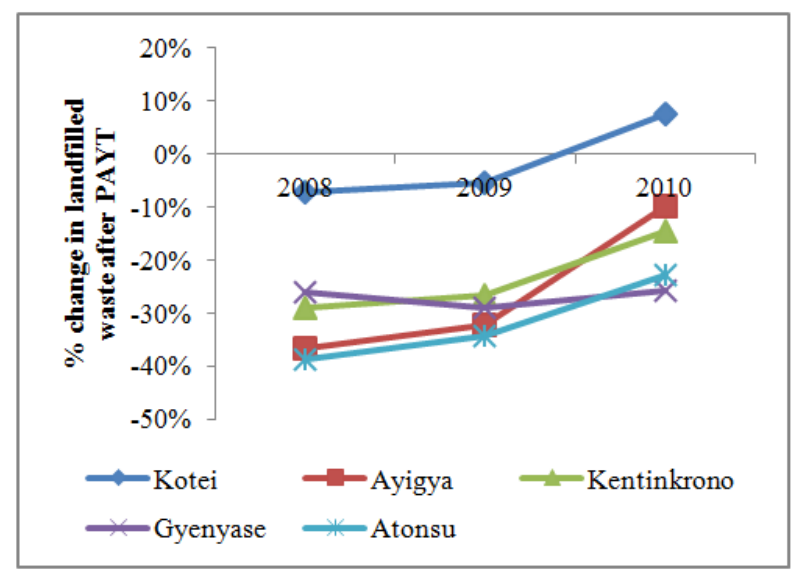

Figure 7. Effect of PAYT on landfilled waste in 2008 to 2010 over 2007 (base year) waste landfilled

The highest percentage change in landfilled waste in 2008 $(-39 \%)$ and $2009(-34 \%)$ as compared to 2007 values were recorded in Atonsu while Gyenyase recorded the highest decline $(-26 \%)$ in 2010 (Figure 6). Averagely, landfilled waste from the five study communities declined by $28 \%, 26 \%$ and 13\% in 2008, 2009 and 2010 respectively, based on 2007 records, indicating a progressive appreciation in landfilled waste. This suggests a lessening public opposition and widespread acceptance of the PAYT system with time.

\section{Conclusion}

The study has shown that an insignificant fraction of the total waste stream ending up at communal collection points is diverted for recycling and reuse purposes. Approximately, $19.4 \pm 9.2 \mathrm{~kg}$ of solid waste is diverted daily by an informal waste picker from each communal collection point in the study communities with no statistically significant difference $(p=0.29)$. This constitutes only $0.5 \mathrm{w} / \mathrm{w} \%$ of the total waste stream at communal collection points and is dependent on the 
storage capacities of the informal waste pickers. This could result in the diversion of about 300tons of solid waste per year from the landfill site, assuming that the practice is replicated in say, 100 communal waste collection points in Kumasi. This translates into a cost savings of about $\mathrm{GH} \phi 18,000 \quad(\approx \mathrm{US} \$ 5,300)$ based on a unit collection and disposal cost of GHф30 ( $\approx$ US\$9) per ton of waste. Higher cost savings could be achieved if there is available market for biodegradables which constitute more than half of the total waste generated in Kumasi.

The diverted waste is largely comprised of plastics (50\%) and metals $(29 \%)$ due to readily available market for these items. Meanwhile, biodegradable components which have the capacity to halve landfilled waste if diverted has no market value in the study area and as a result disposed of without being utilized. The type of items recovered by informal waste pickers is dependent on the existing market value while the quantity of waste recovered depends on the storage capacities of the informal waste pickers. The study has also demonstrated that the introduction of the PAYT system immediately causes a sharp drop (28\% in 2008) in the quantities of waste disposed of at communal collection points but steadily appreciates with time (26\% and $13 \%$ reduction in 2009 and 2010 respectively). The study proposes development of public-private partnerships for solid waste diversion, support and incentives for informal waste pickers and establishment of recycling centres for both currently recovered materials and biodegradable materials. The introduction of the PAYT mechanism must be accompanied with intensive public awareness creation to forestall indiscriminate dumping after its introduction. The research provides a firm foundation to further investigate into waste disposal practices among residents after the introduction of the PAYT mechanism. This would be helpful in ascertaining whether the PAYT mechanism promotes indiscriminate waste disposal at unapproved sites or compels residents to reduce the amount of waste generated.

\section{Acknowledgement}

The authors acknowledge the support of the Waste Management Department of the Kumasi Metropolitan Assembly, Kumasi, Ghana during the course of this study.

\section{References}

[1] Guerrero LA, Ger Maas, G and Hogland W (2012). Solid waste management challenges for cities in developing countries. Waste Management $33: 220-232$

[2] Agboje IA, Adetola, A and Odafe IB (2014). Performance Assessment of Solid Waste Management following Private Partnership Operations in Lagos State, Nigeria. Journal of Waste Management. DOI: http://dx.doi.org/10.1155/2014/868072

[3] Al-Khatib IA, Ajlouny H, Al-Sari', MI and Kontogianni S (2014). Residents' concerns and attitudes toward solid waste management facilities in Palestine: A case study of Hebron
District. Waste Management \& Research 32(3):228-236

[4] World Bank (2012). What a Waste: A Global Review of Solid Waste Management. The World Bank, Urban Development Series $15,8-10$.

[5] Owusu-Sekyere E, Osumanu, IK and Yaro, JA (2013). Dompoase Landfill in the Kumasi Metropolitan Area of Ghana: A 'Blessing' or a 'Curse'?. International Journal of Current Trends in Research 2 (1):87-96

[6] Ketibuah E, Asase M, Yusif S, Mensah MY and Fischer K. (2004). Comparative Analysis of Household Waste in the Cities of Stuttgart and Kumasi-Option for Waste Recycling and Treatment in Kumasi. Proceedings of the 19th international CODATA Conference, 1-8.

[7] Dinye RD (2006). Economies of private sector participation in solid waste management in Takoradi - A Ghanaian City. Journal of Science and Technology. Vol 26 No. 1 53-64

[8] Allesch A. and Brunner P. H. (2014). Assessment methods for solid waste management: A literature review. Waste Management and Research 32(6), 461-473.

[9] Rogoff M (2013). Sustainable materials management: A new international solid waste paradigm Waste Management \& Research. 31(12) 1187-1189

[10] Ramachandra TV (2011). Integrated Management of Municipal Solid Waste. In Garg, S.R. (2011) Environmental Security: Human and Animal Health. IBDC Publishers, India.

[11] Zotos G, Karagiannidis A, Zampetoglou S, Malamakis A, Antonopoulos I.-S, Kontogianni S and Tchobanoglous G (2009). Developing a holistic strategy for integrated waste management within municipal planning: Challenges, policies, solutions and perspectives for Hellenic municipalities in the zero-waste, low-cost direction. Waste Management 29, $1686-1692$.

[12] Jalil A. (2010). Sustainable Development in Malaysia: A Case Study on Household Waste Management. Journal of Sustainable Development. 3(3). 91 - 102

[13] Poulsen TG (2014). Landfilling, past, present and future. Waste Management \& Research 32(3) 177-178.

[14] Annepu R and Themelis NJ (2013). Analysis of Waste Management in Accra, Ghana and Recommendations for further Improvements. Waste-to-Energy Research and Technology Council. Earth Engineering Center, Columbia University

[15] Oduro-Appiah, K, Aidoo, DO and Sarbah G. (2013). Fee-based solid waste collection in economically developing countries: The case of Accra metropolis. International Journal of Development and Sustainability 2(2): 629-639

[16] Senzige JP, Makinde DO, Njau KN, Nkansah-Gyeke Y (2014). Factors Influencing Solid Waste Generation and Composition in Urban Areas of Tanzania: The Case of Dar-es-Salaam. American Journal of Environmental Protection.

[17] Owusu-Sekyere E, Osumanu, IK and Abdul- Kadri Y (2013). An Analysis of the Plastic Waste Collection and Wealth Linkages in Ghana. International Journal of Current Research 5(1), 205-209

[18] Agamuthu P (2013). Landfilling in developing countries. Waste Management and Research 31 (1), 1-2 
[19] Hector G (2008). The Waste of Nations. Adam Smith Research Trust, UK.

[20] Ghana Statistical Service (2013). 2010 Population and Housing Census. National Analytical Report. Accra, Ghana.

[21] Linzner R and Salhofer S (2014). Municipal solid waste recycling and the significance of informal sector in urban China. Waste Management \& Research 1-12 DOI: $10.1177 / 0734242 X 14543555$
[22] Masood M, Barlow CY and Wilson DC (2014). An assessment of the current municipal solid waste management system in Lahore, Pakistan. Waste Management and Research. 1-14. DOI: $10.1177 / 0734242 X 14545373$

[23] Mensah AA (2010). Physico-Chemical Characteristics of Solid Waste and Treatment Options: A Case Study of Kumasi, Ghana. MSc Thesis, Kwame Nkrumah University of Science Technology, Kumasi, Ghana. 